\title{
Degradation of dyes by fungi: an insight into mycoremediation
}

\author{
GeEtanjali Rajhans ${ }^{1}$, Adyasa BariK ${ }^{1}$, SUdiP K. Sen ${ }^{2}$, SANGEeta RaUt ${ }^{1 *}$ \\ ${ }^{1}$ Center for Biotechnology, School of Pharmaceutical Sciences, Siksha 'O' Anusandhan University, Bhubaneswar, Odisha, India \\ ${ }^{2}$ Biostadt India Limited, Waluj, Aurangabad, Maharashtra, India
}

\begin{abstract}
Currently, globalization, urbanization and industrialization have led to several environmental issues. In many industries, particularly in textile industries, the extensive use of synthetic dyes has increased. Dye is an integral element used to impart color to textile materials. Wastes generated during the processing and treatment of the dye contain inorganic and organic compounds that are hazardous, thereby posing a serious threat to the ecosystem. It is therefore important to implement cost-efficient and successful measures against these emissions in order to preserve habitats and natural resources. In this context, biodegradation by fungi or mycoremediation of dyes using potential fungi is a fairly inexpensive and environmental friendly method for decomposing or mineralizing barely or less decaying dye compounds. Fungi play a crucial role in degrading and decolorizing organic dyes by enzymes and processes such as absorption, adsorption and aggregation of effluent colorants. The factors affecting the decolorization and biodegradation of dye compounds through fungal bioremediation, such as $\mathrm{pH}$, temperature, dye concentration, agitation, effects of carbon and nitrogen sources, dye structure, enzymes, electron donor and redox mediators are discussed in this review. The review also includes a summary on the mechanism and kinetics of dye degradation as well as recent advances and future perspectives in mycoremediation of dyes.
\end{abstract}

Key words: Dyes, mycoremediation, decolorization, fungal enzymes

\section{Introduction}

In recent years, contamination of surface water, evaporation and scarcity of clean water are perceived to be major issues for civilization (Moazenzadeh et al., 2018). In addition, the presence of various dyes and toxic organic contaminants in soils and aqueous environments has worsened the condition of global water resources (Shabani et al., 2019). In general, dye is a complex material with a high molecular weight that is water-soluble, degradation-resistant, and plausibly carcinogenic and mutagenic and has the potential to prevent sunlight penetration and thus decrease photosynthetic reactions (Jusoh et al., 2013). Dyes can be categorized as natural and synthetic/artificial. Natural dyes are derived from plant products, including seeds, roots, whole plants, berries, moss, fungi and lichens, while artificial dyes are synthe- sized from chemicals or obtained from earth minerals and petroleum derivatives (Mohd Adnan et al., 2019; Pavithra et al., 2019). Approximately 25 types of dye groups are available based on the chemical structure of their chromophore (Sudha et al., 2014; Benkhaya et al., 2020). There are more than 3000 azo dyes among which Sandolan Yellow, Maxilon Blue GRL and Astrazon Red GTLN are broadly used in leather, textile, paper, food coloring and cosmetic manufacturing industries (Sudha et al., 2014). Dyes can be classified according to their structure and application. On the basis of structure, dyes can be classified as azo dye, nitro dye, phthalein dye, triphenyl methane dye, indigoid dye and anthraquinone dye (Marzec, 2014). On the basis of application, dyes can be classified as acid dye, basic dye, direct dye, ingrain dye, disperse dye, moderate dye, vat dye and reactive

\footnotetext{
* Corresponding author: Center for Biotechnology, School of Pharmaceutical Sciences, Siksha 'O’ Anusandhan University, Bhubaneswar-751003, Odisha, India; e-mail: research.sangeeta@gmail.com
} 
dyes (Hunger, 2007; Lee et al., 2014). More than 1000 dyes have been classified as textile dyes that are used to color a variety of fabrics (Abe et al., 2019). Dyes are highly soluble in water, which makes it difficult to remove them by traditional methods (Dong et al., 2019; Lellis et al., 2019). Textile effluents contain colors that cause aesthetic damage and prevent diffusion of light in the water, which leads to decrease in dissolved oxygen level and affects the photosynthesis rate of aquatic plants (Ajaz et al., 2020). Consequently, dye-containing wastewater can directly disrupt the ecological balance of the water body and negatively affect the health of humans and aquatic organisms (Lai et al., 2019). In comparison, organic dyes (such as azo and fluorescein dyes) are extremely cytotoxic to mammalian tissues and are difficult to decompose naturally (Lin et al., 2012).

Several treatment techniques such as chemical, physical and biological methods have been established to remove dye colorants from textile effluents before discharge (Alneyadi et al., 2018). These methodologies can be categorized into conventional, established and emerging methods of treatment (Rajamani and Rajendrakumar 2019). In addition, oxidation, evaporation, solvent extraction, electrochemical treatment, membrane separation, membrane bioreactors, incineration and ion exchange are among the recovery processes developed for dyes (Crini and Lichtfouse, 2019). Advanced oxidation, adsorption by newly synthesized adsorbents, biosorption, biomass and nanofiltration have emerged as alternative approaches to complement the conventional and established methods (Aziz et al., 2018; Bhattacharyya et al., 2019; Bohutskyi et al., 2019; Cinperi et al., 2019; Londono-Zuluaga et al., 2019). Several drawbacks of traditional approaches, such as unnecessary accumulation of secondary materials, vast output of sludge, inefficiency, high cost and strong propensity to move water-polluting substances to another process, have contributed to the rapid growth of alternative methods such as bioremediation and biosorption (Jusoh et al., 2013; Jaafar et al., 2015).

Bioremediation is an effective, economical and appropriate treatment approach for polluting materials (Maljaei et al., 2009; Guo et al., 2020). It is a method in which waste and toxic chemicals are converted into nonharmful or less toxic compounds by plants and/or microorganisms (Sharma 2021). Numerous microorganisms such as algae, yeast, bacteria, and fungi possess the ability to mineralize and/or decolorize various dyes (Varjani and Upasani, 2019, Kiayi et al., 2019, Li et al., 2019a, Li et al., 2019b, Li et al., 2019c, Pratiwi et al., 2019). Being an economical, eco-friendly and less sludge-producing process, fungal treatment is a very advantageous process used by researchers to find new ways for bioremediation. Contrary to bacteria, fungi robustly degrade multifaceted organic complexes through the production of extracellular ligninolytic enzymes, including manganese peroxidase, laccase and lignin peroxidase; thus, scientists are currently more interested in using fungi for bioremediation (Deska et al., 2019; Guo et al., 2019; Rajhans et al., 2020; Zahran et al., 2019). The method of using fungi in bioremediation is termed as fungal bioremediation or mycoremediation. Fungi have been used for the biotransformation of industrial waste products such as dyes and for eliminating toxins from the ecosystem (Balabanova et al., 2018). They also have the ability to survive and propagate in extreme environmental conditions. Fungi metabolize and immobilize the dyes, either by storing them in different parts of the cell or by translocating them through fungal hyphae and eventually degrading them. Table 1 presents the list of fungi capable of degrading dyes. These features allow fungi as potential candidates to remove dyes from the environment and make them usable for bioremediation in cost-effective and environmental-friendly ways (Zahran et al., 2019). This article focuses on fungi as an enticing alternative to dye degradation.

\section{Factors affecting fungal degradation of dyes}

Fungal degradation of various toxic dyes is significantly affected by variations in specific physico-chemical parameters such as temperature, supplementation of various carbon and nitrogen sources, dye concentration, electron donor, $\mathrm{pH}$, dye structure and redox mediator (Fig. 1).

\section{pH of the medium}

The $\mathrm{pH}$ of the medium has a profound effect on the effectiveness of dye decolorization/degradation. Earlier experiments have shown that the optimal $\mathrm{pH}$ for color removal is often neutral $\mathrm{pH}$ or mild to medium acidic $\mathrm{pH}$ (Hefnawy et al., 2017; Asses et al., 2018). pH tolerance over a wide range is quite important, as it makes fungi suitable for applications in biological treatment of dyecontaining textile effluents. In an earlier study, higher Ponceau 2R dye degradation by Coriolopsis sp. was re- 
Table 1. Reports on the use of fungal cultures for dye degradation

\begin{tabular}{|c|c|c|c|}
\hline Fungi & Dye & Decolorization [\%] & References \\
\hline Coriolopsis sp. & $\begin{array}{l}\text { Crystal Violet } \\
\text { Cotton Blue }\end{array}$ & $\begin{array}{l}85.1 \\
79.6 \\
\end{array}$ & Munck et al. (2018) \\
\hline Peyronellaea prosopidis & Scarlet RR & 90 & Bankole et al. (2018) \\
\hline Aspergillus flavus SA2 & Acid Red 151 and Orange II & 67 & Ali et al. (2018) \\
\hline Aspergillus bombycis & Reactive Red 31 & 99.02 & Khan and Fulekar (2017) \\
\hline Aspergillus niger & Malachite Green & 82.6 & Alam et al.( 2018) \\
\hline Ceriporiala cerata & Congo Red & 90 & Wang et al. (2017b) \\
\hline Scheffersomyces spartinae & Acid Scarlet 3R & $>90 \mathrm{dec}$ & Tan et al. (2016) \\
\hline Cerrena sp. & Malachite Green & 91.6 & Yang et al. (2015) \\
\hline Phanerochaete chrysosporium & $\begin{array}{l}\text { Mixture of Malachite Green, } \\
\text { Nigrosin and Basic Fuchsin }\end{array}$ & 78.4 & Rani et al. (2014) \\
\hline Myceliophthora vellerea & Reactive Blue 220 & 80 & Patel et al. (2013) \\
\hline $\begin{array}{l}\text { Mixed fungal cultures } \\
\text { of Pleurotus ostreatus (BWPH), } \\
\text { Gloeophyllum odoratum (DCa), } \\
\text { and Fusarium oxysporum (G1) }\end{array}$ & Brilliant Green and Evans Blue & 74.3 & Przystaś et al. (2013) \\
\hline Aspergillus sp. & Methyl Violet & 95 & Kumar et al. (2012) \\
\hline Pleurotus ostreatus & Acid Red 27 & 85 & Ali and El-Mohamedy (2012) \\
\hline Pichia sp. & Acid Red B & 95 & Qu et al. (2012) \\
\hline Aspergillus sp. CB-TKL-1 13 & Brilliant Green & 100 & Kumar et al. (2012) \\
\hline
\end{tabular}

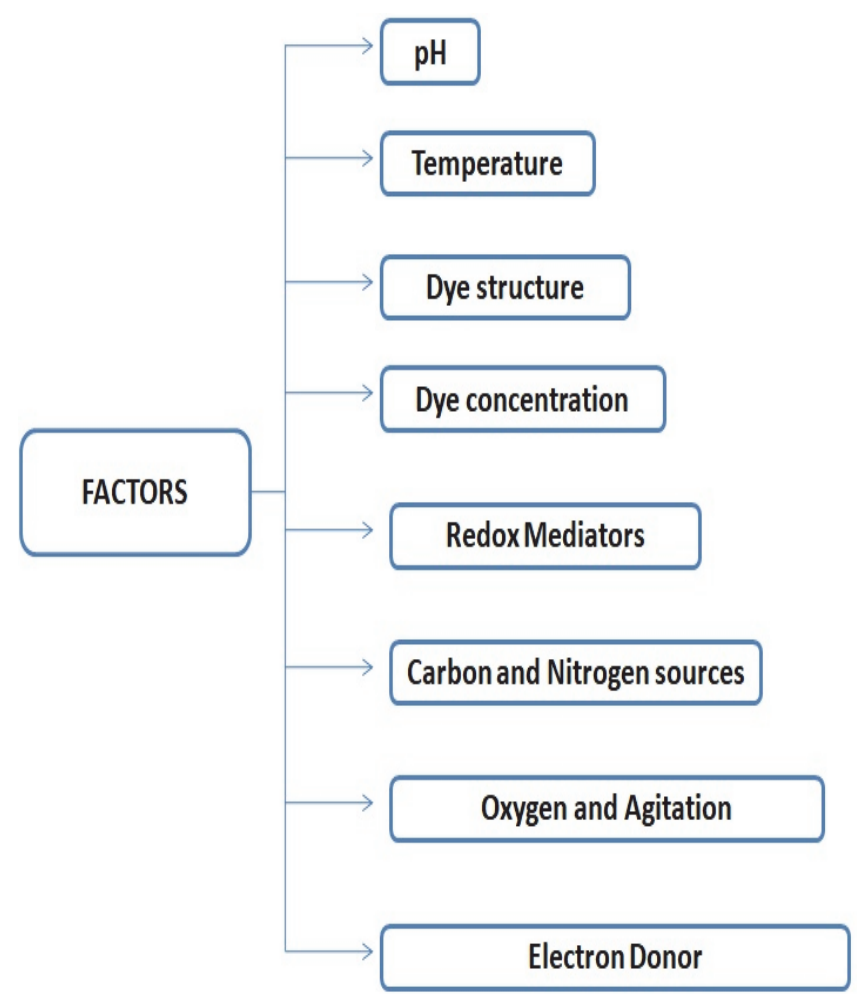

Fig. 1. Factors affecting the degradation of dyes ported at the initial $\mathrm{pH}$ of 4.5 and a lower degradation rate was noted at the initial $\mathrm{pH}$ of 5.0 (Cheng et al., 2016). The authors suggested that the fungus produced acid during the degradation process of azo dyes. Aspergillus niger and Aspergillus flavus were found to efficiently degrade Direct Red dye in the $\mathrm{pH}$ range of 2.0-8.0 (Verma et al., 2019).

\section{Temperature}

The process of fungal decolorization/degradation is directly influenced by temperature because different groups of fungi need a defined range of temperature to perform efficiently. Previous studies have suggested that the rate of color removal increases with an increase in temperature up to a certain limit; thereafter, there is a marginal reduction in the decolorization activity (Kalyani et al., 2016; Hefnawy et al., 2017). Better decolorization efficiency of the azo dye reactive violet 1 by Ganoderma cupreum AG-1 was observed in the lower incubation temperature range $\left(25-35^{\circ} \mathrm{C}\right)$ (Ameen et al. 2021). A recent study showed that the optimal temperature range for dye decolorization by an Aspergillus strain was 


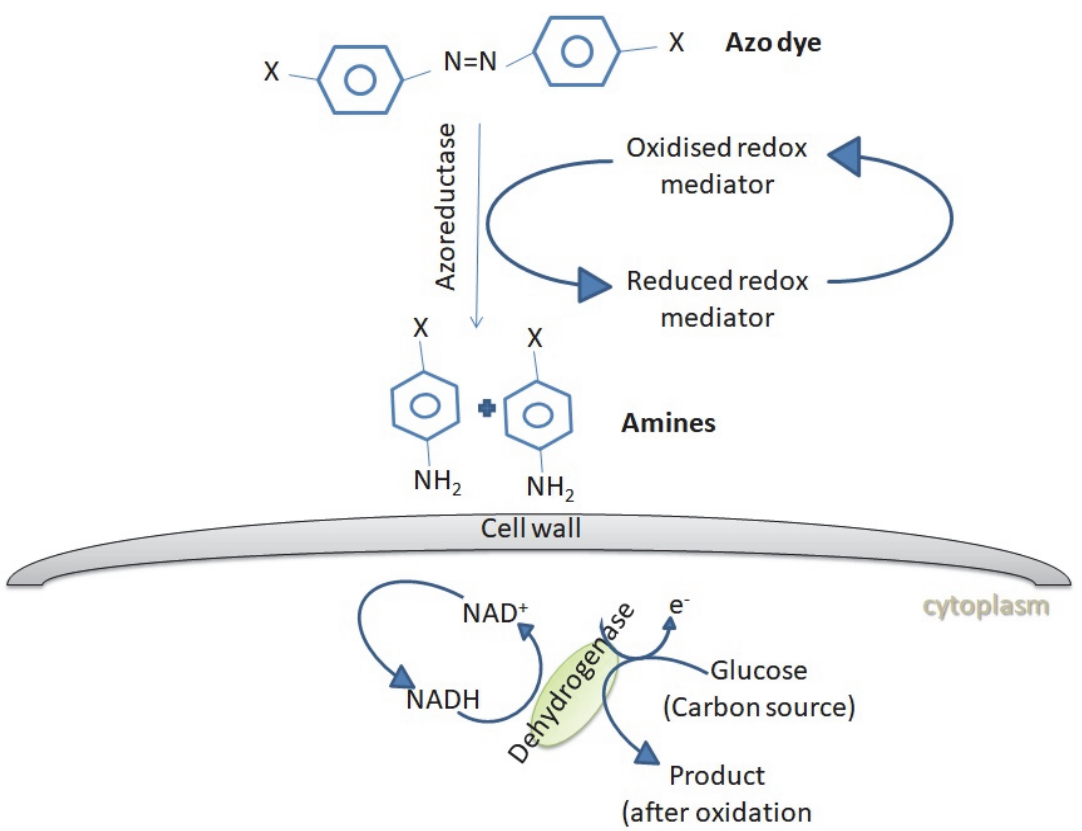

Fig. 2. Azo dye degradation by fungi. Fungi produces enzymes such as azoreductases, which can degrade azo dyes through reductive cleavage into colorless amines in the presence of reducing agents such as FADH or NADH (Singh et al., 2015)

$30-35^{\circ} \mathrm{C}$ (Ameen et al., 2021). On the other hand, elevated temperature $\left(60-70^{\circ} \mathrm{C}\right)$ supported the enzymatic activity and decolorization of polymeric dyes by different fungal strains, as reported by Blánquez et al. (2019).

\section{Structure and concentration of dyes}

The structure and concentration of dyes strongly influence their degradation/decolorization efficiency. Low dye concentration may not be detected by enzymes secreted from dye-degrading fungi. High dye concentration, on the other hand, is toxic to fungi and can also affect the degradation of dye by blocking the enzyme active sites. Likewise, it is easy to decolorize dyes with a simple structure and low molecular weight. Dyes with a high molecular weight and a complex structure, however, have a low decolorization rate (Li et al., 2019b). The increase in dye concentration prevents dye degradation and/or decolorization (Liu et al., 2017).

In a study on Congo Red decolorization and detoxification by $A$. niger, it was observed that the dye removal was slightly inhibited at $0.5 \mathrm{~g} / 1$ Congo Red concentration, and the best result was obtained at $0.25 \mathrm{~g} / 1$ concentration of Congo Red, with a decolorization rate of $96 \%$. As the initial dye concentration increased to $1 \mathrm{~g} / \mathrm{l}$, a significant reduction in the decolorization rate was observed (73\%), which could be due to higher toxicity at higher dye concentration (Asses et al., 2018). Yet another study on
Congo Red decolorization by Ceriporia lacerata showed the decolorization rate to exceed $85 \%$ at low dye concentration (including $0.05,0.1,0.25$ and $0.5 \mathrm{mg} / \mathrm{ml}$ ) (Wang et al., 2017). With the increase in dye concentration, the decolorization rate was reduced. Additionally, it was observed that with the increase in dye molecules per unit volume, the fungal growth was inhibited due to enhanced stress, and the degradation ability of the enzymes decreased because of reduction in the amount of enzymes (Cheng et al., 2012; Yang et al., 2012).Wang et al. also observed that the surface charges of the mycelia and the structure of dye molecules were affected by $\mathrm{pH}$ during the adsorption process. When the $\mathrm{pH}$ value is greater than the isoelectric point of the mycelia, the surface shows a negative charge, whereas when the $\mathrm{pH}$ value is lower than the isoelectric point of the mycelia, the surface shows a positive charge. The surface charge of the mycelia in the dye solution is stable when the $\mathrm{pH}$ value is equal to the isoelectric point (Lin et al., 2012). The structure of Congo Red molecules can also change as the $\mathrm{pH}$ value changes. As the $\mathrm{pH}$ falls below 5.2, the amino groups absorb $\mathrm{H}^{+}$, causing the dye molecules to take on a positive charge; hence,the surface charge shifts from positive to negative as the $\mathrm{pH}$ value increases (Yang et al., 2011). Because the same charges between the dye molecules and the mycelia repel each other at acidic and alkaline $\mathrm{pH}$ values, the decolorization rate was found to 
be low. Positive and negative charges on the surface of the dye molecules and the fungal mycelia were balanced in the neutral environment, and the dye molecules were adsorbed by the fungal mycelia, resulting in the highest decolorization rate (Legorreta-Castañeda et al., 2020).

\section{Carbon and nitrogen sources}

Fungi require nutrient supplements such as carbon and nitrogen for their growth and for the degradation of contaminants. Glucose, fructose, sucrose, etc. have been widely investigated as carbon sources for the growth of fungi, while starch and xylan also seem to be valuable carbon sources (Pawłowska et al., 2019). Each additional carbon source showed a positive effect in the decolorization of dye wastewater. The maximum decolorization (89.2\%) of synthetic textile dye wastewater by Phanerochaete chrysosporium was obtained when rice bran was used as an additional carbon source to supplement other carbon sources (Kiran et al., 2019). A study conducted by Sweety et al. (2017) showed that the optimized amounts of nitrogen sources for the fungal (Trichoderma virens, Phlebiopsis cf. ravenelii, Talaromyces stipitatus and $A$. niger) degradation of azo dyeswere $0.5 \%$ and $0.2 \%$ of ammonium sulfate and sodium nitrate, respectively. The authors also found that the optimized amounts of carbon sources for the degradation of azo dyes were $1 \%$ and $0.5 \%$ of glucose and lactose, respectively. The addition of a nitrogen source at the concentration above $0.5 \%$ decreased the percentage of decolorization, whereas the decolorization rate increased with further increase in concentration of the carbon source to upto 0.5\% (Sweety et al., 2017). However, a study by Akdogan et al. (2014) showed that higher concentrations of carbon sources (glucose, maltose and fructose) did not contribute to higher decolorization of Reactive Blue 19, and the yield of decolorization was very low with some carbon sources (glycerol and starch). Some nitrogen substrates such as sodium nitrate, ammonium tartrate and ammonium oxalate promoted decolorization, while some other nitrogen sources such as urea and ammonium chloride were inhibitory. A significant observation indicated that the effect of a nitrogen source can depend on the accompanying carbon substrate. Thus, soluble extracts derived from cultures containing $5 \mathrm{~g} / \mathrm{l}$ urea led to a $10 \%$ decolorization of Reactive Blue 19 when combined with $5 \mathrm{~g} / \mathrm{l}$ fructose in the culture medium; however, when combined with glucose, this same concentration of urea yielded a 5-fold higher decolorization rate. A similar effect was observed for 10 and $15 \mathrm{~g} / 1$ ammonium oxalate with fructose and glucose (Akdogan et al., 2014).

\section{Redox mediators}

Redox mediators (RMs) are molecules that reversibly oxidize and reduce dye compounds on the basis of their capacity to serve as an electron carrier in multiple redox reactions. They are known to accelerate reactions by lowering the activation energy of the total reaction (Tamirat et al. 2020). However, in certain cases, the presence of RMs may even be a prerequisite for the reaction to occur. Flavin-based compounds such as flavin adenine dinucleotide (FAD) and flavin adenine mononucleotide (FMN) and quinone-based compounds such as anthraquinone 2,6-disulfonate (AQDS) and anthraquinone2-sulfonate (AQS), riboflavin (vitamin B2), cyanocobalamin (vitamin B12) and lawsone (2-hydroxy-1,4-naphthoquinone) are well-known RMs (Sun et al., 2013). A very small concentration of RMs is sufficient to accelerate electron transfer and is characterized by a redox potential ranging from -200 to $-350 \mathrm{mV}$. The stimulating performance of the RMs is dependent on the redox potential. Therefore, an electron shuttling compound will only be effective as an RM for azo dye reduction if it lowers the activation energy of the reaction. In a previous study, the effects of seven RMsincluding ABTS, vanillin, vanillic acid, 4-nitrophenol, veratyl alcohol, 1-naphthol and 2-naphthol were observed on the degradation of Rhodamine B by Trametes versicolor (Khammuang and Sarnthima, 2009). ABTS enabled to achieve highest decolorization of Rhodamine $\mathrm{B}$ by more than $80 \%$ within $48 \mathrm{~h}$, while only $20 \%$ decolorization could be achieved without the mediator.

Another study investigated the effect of RM such as acetosyringone and ABTS on the degradation of Remazol Brilliant Blue R (RBBR), Lanasey Grey, Congo Red and Poly R-478 by laccases from Cerrena unicolor and Trametes hirsuta (Moilanen et al., 2010). The authors found that $C$. unicolor laccase did not require any mediators for removing the dyes. However, T. hirsuta laccase could decolorize only simulated Congo Red and RBBR dye baths ( $91 \%$ and $45 \%$, respectively) in $19.5 \mathrm{~h}$ without mediators. When using mediators, the decolorization capability was enhanced substantially, for example, Poly R-478 was decolorized by $78 \%$ in 25.5 h (Moilanen et al., 2010). 


\section{Agitation/shaking and oxygen}

The environmental conditions directly affect the degradation/decolorization of dyes. Previous studies have shown that microbial metabolism is highly influenced by oxygen and agitation(Varjani and Upasani, 2019). Agitation plays an active role in aeration/oxygen supply. It is assumed that reductive enzyme activities can be increased under anaerobic condition (Khan et al., 2012). Aerobic dye degradation, however, involves the use of oxidative enzymes, which require oxygen (Khan et al., 2012). González-Gutierrez-de-Lara and Gonzalez-Martinez (2017) studied Direct Blue 2 dye degradation under different oxygen concentrations. The authors found that decreasedair flow caused a subsequent decrease in the concentration of dissolved oxygen, while increasing the dye removal rate. Bettin et al. (2019) conducted a study on decolorization of 22 different dyes using laccases produced by Pleurotus sajor-caju PS-2001 under agitation $(100 \mathrm{rpm})$ at $\mathrm{pH} 3.2$ and temperatures of 30 and $35^{\circ} \mathrm{C}$ under reciprocal agitation of $100 \mathrm{~min}^{-1}$. The authors found that the percentages of decolorization with agitation were much lower than those obtained under static conditions using the same $\mathrm{pH}$ values and temperature. The agitation of the reaction medium induced a negative effect on decolorization (Bettin et al., 2019). On the other hand, Kaushik and Malik (2009) observed that in various studies involving fungal remediation of dyes, decolorization increased when the process was performed under agitation in comparison that when using a stationary culture. These results seemed to be associated with enhanced oxygen transfer and nutrient distribution during agitation.

\section{Mechanism of dye degradation}

The dye degradation or dye removal process mediated by fungi may be categorized into biosorption, bioaccumulation and biodegradation. Adsorption of dyes onto the microbial cell surface is the primary mechanism of decolorization (Kaushik et al., 2015). Almeida and Corso (2014) reported the bioadsorption and degradation of Procion Red MX-5B by A. niger and Aspergillus terreus. Fungal biomass can be applied as a biosorbent in both living and dead states. Living fungal cells use metabolic activities to treat dye wastewaters, while dead biomass relies on physical and chemical removal mechanisms (Srinivasan and Viraraghava, 2010; Grainger et al., 2011). The dead fungal biomass contains a natural poly- saccharide chitin and its derivative chitosan in their cell walls, which has a unique molecular structure with a high affinity for many classes of dyes (Criniand Badot, 2008). Bioaccumulation is an energy and metabolically dependent process, where actively growing cells accumulate the pollutants inside their cytoplasm (Kaushik and Malik, 2013; Mathur et al., 2017). Biodegradation is also an energy-intensive and metabolically dependent process, where the complex dye molecules are broken down into simpler molecules through the action of certain enzymes (Singh, 2017). Figure 2 shows the schematic representation of dye biodegradation by fungi.

\section{Kinetics and modeling of microbial degradation of dyes}

The kinetics of bioremediation of dyes is greatly affected by experimental conditions such as $\mathrm{pH}$, incubation period, biomass amount, initial concentration of dye, agitation speed, and type of microbial strain (Roy et al., 2018; Ishchi and Sibi, 2020). To properly assess the effects of these kinetic parameters on the overall bioremediation rate, statistical analysis such as RSM (Response Surface Methodology) is recommended for modeling and optimizing a variety of wastewater treatment technologies, as this method generates simulated data for variables operating under specifically designed experimental conditions (Alalm et al., 2016; Ateia et al., 2016; Mahmoud et al., 2017). As dyes are colored compounds, the kinetics of their bioremediation is assessed by measuring their color intensity (e.g., by UV/Vis spectroscopic analysis) (da Silva et al., 2016). The color of dye is gradually diminished with the breakage of the chemical bonds responsible for color. Hence, any factor that can affect the breakage of the chemical bonds of dyes can also affect the rate of bioremediation. In this respect, adsorption of dyes onto biosorbents is the key factor that can substantially control the remediation process (Argun et al., 2017). The rate of decolorization of dye can be determined using equation (1):

$$
q_{e}=\left(C_{o}-C_{e}\right) \times \frac{v}{m}
$$

where $q_{e}, C_{o}, C_{e}, v$, and $\mathrm{m}$ are the $\mathrm{mg}$ of dye adsorbed per gram of biomass solution, initial concentration of dye in $\mathrm{mg}$, concentration of dye at equilibrium, volume in liters, and biomass weight in grams, respectively (Ayawei et al., 2017). This equation is called an adsorption isotherm, and it can be used to explain the functional 
equilibrium distribution of adsorption in relation to adsorbate concentration in solution at a fixed temperature (Ayawei et al., 2017). Moreover, adsorption isotherms can help to determine the feasibility of the bioremediation process for a specific application and in the selection of a suitable adsorbent and its appropriate dose (Ayawei et al., 2017). It is known that the adsorption of dye on a biosorbent can occur either in a monolayer or in a multilayer pattern, which can be best represented by Langmuir's and Freundlich's isotherms, respectively (Chung et al., 2015). In situations when a plot of $C_{d} / q_{e}$ versus $C_{e}$ produces a straight line, the Langmuir isotherm can be used to suitably represent the adsorption process of textile dyes on biosorbents (Chung et al., 2015). In contrast, Freundlich isotherms are applicable to data for which a straight line is obtained by plotting $\log q_{e}$ versus $\log C_{e}$. For the latter isotherms, it is assumed that the adsorption of dyes should occur in a multilayer pattern due to the infinite number of adsorption sites on the biosorbent. In addition, an infinite number of adsorption sites on biosorbents require a relatively long time for complete saturation with dyes (Chung et al., 2015). Langmuir adsorption isotherms represent monolayer adsorption of dyes on a finite number of active sites of biosorbents, which can be fully saturated in a short amount of time. Moreover, the amount of dyes adsorbed in monolayer adsorption is moderately smaller than that in multilayer adsorption (Amin et al., 2014).

\section{Future perspectives}

Future works on fungal degradation of dyes should focus on minimizing the limitation factors that affect fungal activities. To develop fungal activities for better performance, the re-examination of recent and early successful studies should be carried out. An effective biodegradation process should consider degradation pathways, environmental factors, degradation rate and degradation mechanisms that affect the removal of dye pollutants. It is highly imperative to ensure that the degraded products are not toxic to aquatic life or plants. Integration of different treatment technologies for dye pollutants is highly desirable for effective translation to industries. The study of mechanisms and theories for fungal degradation of dye wastewater would help to explore fungal degradation kinetics.

\section{Conclusions}

Water contamination due todyeing industries is a critical issue as large quantities of effluentsare discharged into the water bodies. The effectiveness of the microbial cycle for the removal/degradation of dyes from the effluent relies on the use of microorganisms that effectively decolor/degrade synthetic dyes with various chemical structures. Fungal degradation/decolorization of textile dyes has been primarily investigated in laboratory studies. The utilization of fungi in dye decolorization is still under investigation to assess the information on process implementation. The findings obtained mainly from laboratory tests rely on the appropriate growth medium and parameter optimization (addition of co-substrates, nutrients, mediator molecules and optimization of physical parameters) and adequate handling of fungal strains or biomass. Integration of technologies is yet another important aspect which could bring potential benefits. Advanced technologies and materials need to be developed for effective degradation of dyes in industrial wastewater. Essential studies are therefore currently on going in laboratories and on a commercial scale to solve the problem of colorants in effluents through my core mediation.

\section{Acknowledgments}

This study was funded by the Department of Science and Technology (DST/SSTP/Odisha/443), and this financial support is greatly acknowledged. We express our gratitude toward the Center for Biotechnology, Siksha 'O' Anusandhan (Deemed to be University), Bhubaneswar, for their support and encouragement.

\section{References}

Abe F.R., Machado A.L., Soares A.M.V.M., de Oliveira D.P., Pestana J.L.T. (2019) Life history and behavior effects of synthetic and natural dyes on Daphnia magna. Chemosphere 236: 124390.

Ajaz M., Shakeel S., Rehman A. (2020) Microbial use for azo dye degradation-a strategy for dye bioremediation. Int. Microbiol. 23(2): 149-159.

Akdogan H.A., Topuz M.C., Urhan A.A. (2014) Studies on decolorization of reactive blue 19 textile dye by Coprinusplicatilis. J. Environ. Health Sci. Engineer. 12: 49.

Alalm M.G., Nasr M., Ookawara S. (2016) Assessment of a novel spiral hydraulic flocculation/sedimentation system by CFD simulation, fuzzy inference system, and response surface methodology. Sep. Purif. Technol. 169: 137-150. 
Alam M.Z., Khan M.J.H., Kabbashi N.A., Sayem S.M.A. (2018) Development of an effective biosorbent by fungal immobilization technique for removal of dyes. Waste Biomass Valor. 9: 681-690.

Ali N.F., El-Mohamedy R.S.R. (2012) Microbial decolorization of textile waste water. J. Saudi. Chem. Soc. 16 (2): 117-123.

Almeida E.J.R., Corso C.R. (2014) Comparative study of toxicity of azo dye procion red $M x-5 b$ following biosorption and biodegradation treatments with the fungi Aspergillus niger and Aspergillus terreus. Chemosphere. 112: 317-322.

Alneyadi A.H., Rauf M.A., Ashraf S.S. (2018) Oxidoreductases for the remediation of organic pollutants in water - a critical review. Crit. Rev. Biotechnol. 38(7): 971-988.

Ameen F., Dawoud T.M., Alshehrei F., Alsamhary K., Almansob A. (2021) Decolorization of acid Blue 29, disperse Red 1 and Congo Red by different indigenous fungal strains. Chemosphere 271: 129532.

Amin M.T., Alazba A.A., Manzoor U. (2014) A review of removal of pollutants from water/wastewater using different types of nanomaterials. Adv. Mater. Sci. Eng. 2014: 1-24.

Argun Y.A., Karacali A., Calisir U., Kilinc N., Irak H. (2017) Biosorption method and biosorbents for dye removal from industrial wastewater: a review. Int. J. Adv. Res. 5: 707-714.

Asses N., Ayed L., Hkiri N., Hamdi M. (2018) Congo Red Decolorization And Detoxification By Aspergillus Niger: Removal Mechanisms And Dye Degradation Pathway. Biomed. Res. Int. 3049686.

Ateia M., Nasr M., Ikeda A., Okada H., Fujii M., Natsuike M., Yoshimura C. (2016) Nonlinear relationship of near-bed velocity and growth of riverbed periphyton. Water. 8(10): 461.

Ayawei N., Ebelegi A.N., Wankasi D. (2017) Modelling and interpretation Of Adsorption Isotherms. J. Chem. 2017: 1-11.

Aziz F.F.A., Jalil A.A., Triwahyono S., Mohamed M. (2018) Controllable structure of fibrous SiO 2 - ZSM-5 support decorated with TiO 2 catalysts for enhanced photodegradation of paracetamol. Appl. Surf. Sci. 455: 84-95.

Balabanova L., Slepchenko L., Son O., Tekutyeva L. (2018) Biotechnology potential of marine fungi degrading plant and algae polymeric substrates. Front. Microbiol. 9: 1527.

Bankole P.O., Adekunle A.A., Obidi O.F., Chandanshive V.V. Govindwar S.P. (2018) Biodegradation and detoxification of Scarlet $R R$ dye by a newly isolated filamentous fungus, Peyronellaea prosopidis. Sustain. Environ. Res. 28(5): 214-222.

Benkhaya S., M'rabet S., El Harfi A. (2020) Classifications, properties, recent synthesis and applications of azo dyes. Heliyon. 6(1): 03271.

Bettin F., Cousseau F., Martins K., Zaccaria S., Girardi V., Silveira M.M., Dillon A.J. (2019) Effects of $p H$, temperature and agitation on the decolourisation of dyes by Laccasecontaining enzyme preparation from Pleurotussajor-caju. Braz. Arch. Biol. Technol. 62: 19180338.

Bhattacharyya S., Das P., Datta S. (2019) Removal of ranitidine from pharmaceutical wastewater using activated carbon $(A C)$ prepared from waste Lemon Peel. [In:] Ghosh S. (eds) Wastewater recycling and management. Springer, Singapore.
Blánquez A., Rodríguez J., Brissos V., Mendes S., Martins L.O., Ball A.S., Arias M.E., Hernández M. (2019) Decolorization and detoxification of textile dyes using a versatile Streptomyces laccase-natural mediator system. Saudi J. Biol. Sci. 26(5): 913-920.

Bohutskyi P., Phan D., Spierling R.E., Kopachevsky A.M., Bouwer E.J., Lundquist T.J., Betenbaugh M.J. (2019) Production of lipid-containing algal-bacterial polyculture in wastewater and biomethanation of lipid extracted residues: enhancing methane yield through hydrothermal pretreatment and relieving solvent toxicity through co-digestion. Sci. Total Environ. 653: 1377-1394.

Cheng W.N., Sim H.K., Ahmad S.A., Syed M.A., Shukor Y., Yusof M.T. (2016) Characterization of an azo-dye-degrading white rot fungus isolated from Malaysia. Mycosphere 7: 560-569.

Cheng Z.Z., Yang Z.P., H, R., Jing D.J., Chen H.P. (2012) Decolorization of 12 kinds of dyes by the mycelium pellets of Trametesgallica under non-sterile condition. Mycosystema 31 (6): 878-889.

Chung H., Kim W., Park J., Cho J., Jeong T., Park P. (2015) Application of langmuir and freundlich isotherms to predict adsorbate removal efficiency or required amount of adsorbent. J. Ind. Eng. Chem. 28: 241-246.

Cinperi N.C., Ozturk E., Yigit N.O., Kitis M. (2019) Treatment of woolen textile wastewater using membrane bioreactor, nanofiltration and reverse osmosis for reuse in production processes. J. Clean. Prod. 223: 837-848.

Crini G., Badot P.M. (2008) Application of chitosan, a natural aminopolysaccharide, for dye removal from aqueous solutions by adsorption processes using batch studies: a review of recent literature. Prog. Polym. Sci. 33: 399-447.

Crini G., Lichtfouse E. (2019) Advantages and disadvantages of techniques used for wastewater treatment. Environ. Chem. Lett. 17: 145-155.

da Silva L.C., de Lima D.F. Silva J.A., Morais C., Albuquerque B., Bortoluzzi A.J., Domingos J., Araújo R.M., Menezes F., Lima K. (2016) Quantification of synthetic amino-nitroquinoxaline dyes: an approach using image analysis. J. Braz. Chem. Soc. 27(7): 1067-1077.

Deska M., Kończak B. (2019) Immobilized fungal laccase as "Green catalyst" for the decolourization process - state of the art. Process Biochem. 84: 112-123

Dong H., Guo T., Zhang W., Ying H., Wang P., Wang Y., Chen Y. (2019) Biochemical characterization of a novel azoreductase from Streptomyces sp.: application in eco-friendly decolorization of azo dye wastewater. Int. J. Biol. Macromolecules 140: 1037-1046.

González-Gutiérrez-de-Lara E., González-Martínez S. (2017) Simultaneous treatment of wastewater and direct Blue 2 azo dye in a biological aerated filter under different oxygen concentrations. [In:] Mannina G. (eds) Frontiers in wastewater treatment and modelling. FICWTM 2017. Lecture Notes in Civil Engineering 4. Springer, Cham. 376-381. 
Grainger S., Fu G.Y., Hall E.R. (2011) Biosorption of colourimparting substances in biologically treated pulp mill effluent using Aspergillus niger fungal biomass, Water Air Soil Pollut. 217: 233-244.

Guo G., Li X., Tian F., Liu T., Yang F., Ding K., Liu C., Chen J., Wang C. (2020) Azo dye decolorization by a halotolerant consortium under microaerophilic conditions. Chemosphere. 244: 125510.

Guo G., Tian F., Zhang C., Liu T., Yang F., Hu Z., Liu C., Wang S., Ding K. (2019) Performance of a newly enriched bacterial consortium for degrading and detoxifying azo dyes. Water Sci. Technol. 79: 2036-2045.

Hefnawy M.A. Gharieb M.M., Shaaban M.T., Soliman A.M. (2017) Optimization of culture condition for enhanced decolorization of direct blue dye by Aspergillusflavus and Penicilliumcanescens. J. Appl. Pharm. Sci. 7(02): 083-092.

Hunger K. (2007) Industrial dyes: chemistry, properties, applications. Wiley-VCH: Weinheim. 2003. 660 pp. Org. Proc. Res. Dev. 8(2): 296-297.

Ishchi T., Sibi G. (2020) Azo Dye Degradation by Chlorella vulgaris: Optimization and Kinetics. Int. J. Biol. Chem. 14: 1-7.

Jaafar N.F., Jalil A.A., Triwahyono S., Efendi J., Mukti R.R., Jusoh R., Jusoh N.W.C., Karim A.H., Salleh N.F.M., Suendo V. (2015) Direct in situ activation of AgO nanoparticles in synthesis of $\mathrm{Ag} / \mathrm{TiO} 2$ and its photoactivity. Appl. Surf. Sci. 338: 75-84.

Jusoh N.W.C., Jalil A.A., Triwahyono S., Setiabudi H.D., Sapawe N., Satar M.A.H., Karim A.H., Kamarudin N.H.N., Jusoh R., Jaafar N.F., Salamun N., Efendi J. (2013) Sequential desilication-isomorphous substitution route to prepare mesostructured silica nanoparticles loaded with $\mathrm{ZnO}$ and their photocatalytic activity. Appl. Catal. A: Gen. 468: 276-287.

Kalyani P., Hemalatha V., Vineela K., Hemalatha K.P.J. (2016) Degradation of Toxic Dyes- A Review. Int. J. Pure App. Biosci. 4(5): 81-89.

Kaushik P., Malik A. (2009) Fungal dye decolourization: Recent advances and future potential. Environ. Int. 35(1): 127-141.

Kaushik P., Malik A. (2013) Comparative Performance Evaluation of Aspergillus Lentulus For Dye Removal Through Bioaccumulation and Biosorption. Environ. Sci. Pollut. Res. 20: 2882-2892.

Kaushik P., MalikA. (2015) Mycoremediation of synthetic dyes: An insight into the mechanism, process optimization and reactor design. [In:] Singh SN editor. Microbial Degradation of Synthetic Dyes in Wastewaters. Environmental Science and Engineering, Switzerland: Springer International Publishing 1-25.

KhammuangS., Sarnthima R. (2009) Mediator-Assisted Rhoda mine B Decolorization by Tramatesversicolor Laccase. Pakistan Journal of Biological Sciences. 12: 616-623.

Khan R., Pathak B., Fulekar M.H. (2012) Microbial decolorization and degradation of synthetic dyes: A review. Rev. Environ. Sci. Biotechnol. 12.
Khan R., Fulekar M.H. (2017) Mineralization of a sulfonated textile dye Reactive Red 31 from simulated wastewater using pellets of Aspergillus bombycis. Bioresour. Bioprocess. 4 (1): 23.

Kiayi Z., Lotfabad T.B., Heidarinasab A., Shahcheraghi F. (2019) Microbial degradation of azo dye carmoisine in aqueous medium using Saccharomyces cerevisiae ATCC 9763. J. Hazard. Mater. 373: 608-619.

Kiran S., Huma T., Jalal F., Farooq T., Hameed A., Gulzar T., Bashir A., Rahmat M., Rahmat R., Rafique M.A. (2019) lignin degrading system of Phanerochaete chrysosporium and its exploitation for degradation of synthetic dyes wastewater, Pol. J. Environ. Stud. 28(3): 1749-1757.

Kumar C.G., Mongolla P., Joseph J., Sarma V.U.M. (2012) Decolorization and biodegradation of triphenylmethane dye, brilliant green, by Aspergillus sp. isolated from Ladakh, India. Process Biochem. 47(9): 1388-1394.

Lai X., Guo R., Xiao H., Lan J., Jiang S., Cui C., Ren E. (2019) Rapid microwave-assisted bio-synthesized silver/Dandelion catalyst with superior catalytic performance for dyes degradation. J. Hazard Mater. 371: 506-512.

Lee M.J., Ho C.C., Lin H., Wang P., Lu J. (2014) Solubility of Disperse Red 82 and modified Disperse Yellow 119 in supercritical carbon dioxide or nitrous oxide with ethanol as a cosolvent. J. Supercrit. Fluids. 95: 258-264.

Legorreta-Castañeda A.J., Lucho-Constantino C.A., BeltránHernández R.I., Coronel-Olivares C., Vázquez-Rodríguez G.A. (2020) Biosorption of Water Pollutants by Fungal Pellets. Water 12(4): 1155.

Lellis B., Favaro-Polonio C.Z., Pamphile J.A., Polonio J.C. (2019) Effects of textile dyes on health and the environment and bioremediation potential of living organisms. Biotechnol. Res. Innovation. 3(2): 275-290.

Li N., Chen G., Zhao J., Yan B., Cheng Z., Meng L., Chen V. (2019a) Self-cleaning PDA/ZIF-67@PP membrane for dye wastewater remediation with peroxymonosulfate and visible light activation. J. Membr. Sci. 591: 117341.

Li J.F., Rupa J.E., Hurh J., Huo Y., Chen L., Han Y., Ahn J.C., Park J.K., Lee H.A., Mathiyalaganb R., Yang D.C. (2019b) Cordycepsmilitaris fungus mediated Zinc Oxide nanoparticles for the photocatalytic degradation of Methylene blue dye. Optik. 183: 691-697.

Li, H., Wang Y., Wang Y., Wang H., Sun K., Lu Z. (2019c) Bacterial degradation of anthraquinone dyes. J. Zhejiang UniSci. B. 20 (6): 528-540.

Lin J.M., Zhang Y.P., Wu P.Y., Lin J.Q., Duan J.M. (2012) Experimental study on degradation of cationic red GTL by White-rot Fungi. Environ. Sci. Technol. 35 (1): 89-94.

Liu N, Xie X.H., Yang B. (2017) Performance and microbial community structures of hydrolysis acidification process treating azo and anthraquinone dyes in different stages. Environ. Sci. Pollut. Res. 24(1): 252-263.

Londono-Zuluaga C., Jameel H., Gonzalez R.W., Lucia L. (2019) Crustacean shell-based biosorption water remediation platforms: Status and perspectives. J. Environ. Manage. 231: 757-762. 
Mahmoud M.S., Mostafa M.K., Mohamed S.A., Sobhy N., Nasr M. (2017) Bioremediation of red azo dye from aqueous solutions by Aspergillus niger strain isolated from textile wastewater. J. Environ. Chem. Eng. 5(1): 547-554.

Maljaei A., Arami M., Mahmoodi N.M. (2009) Decolorization and aromatic ring degradation of colored textile wastewater using indirect electrochemical oxidation method. Desalination. 249(3): 1074-1078.

Mathur M., Gola D., Panja R., Malik A., Ahammad S.Z. (2017) Performance Evaluation of Two Aspergillus Spp. For The Decolourization of Reactive Dyes by Bioaccumulation and Biosorption. Environ. Sci. Pollut. 25(1): 345-352.

Marzec A. (2014) The effect of dyes, pigments and ionic liquids on the properties of elastomer composites. Polymers. Université Claude Bernard - Lyon I; Uniwersytet Łódzki.

Moazenzadeh R., Mohammadi B., Shamshirband S., Chau K. (2018) Coupling a firefly algorithm with support vector regression to predict evaporation in northern Iran. Eng. Appl. Fluid Mech. 12(1): 584-597.

Moilanen U., Osma J.F., Winquist E., Leisola M., Couto S.R. (2010) Decolorization of simulated textile dye baths by crude laccases from Trameteshirsuta and Cerrena unicolor. Eng. Life Sci. 10(3): 242-247.

Mohd Adnan M.A., Muhd Julkapli N., Amir M.N.I., Maamor A. (2019) Effect on different TiO2 photocatalyst supports on photodecolorization of synthetic dyes: a review. Int. J. Environ. Sci. Technol. 16: 547-566.

Munck C., Thierry E., Gräßle S., Chen S.H., Ting A.S.Y. (2018) Biofilm formation of filamentous fungi Coriolopsis $s p$. on simple muslin cloth to enhance removal of triphenylmethane dyes. J. Environ. Manage. 214: 261-266.

Patel V.R., Bhatt N.S., B Bhatt H. (2013) Involvement of ligninolytic enzymes of Myceliophthoravellerea HQ871747 in decolorization and complete mineralization of Reactive Blue 220. Chem. Eng. Technol. 233: 98-108.

Pavithra K.G., Senthil Kumar P., Jaikumar V., SundarRajan P. (2019) Removal of colorants from wastewater: A review on sources and treatment strategies. J. Ind. Eng. Chem. 75: $1-19$.

Pawłowska J., Okrasińska A., Kisło K., Aleksandrzak-Piekarczyk T., Szatraj K., Dolatabadi S., Muszewsk A. (2019) Carbon assimilation profiles of mucoralean fungi show their metabolic versatility. Sci. Rep. 9: 11864.

Pratiwi D., Prasetyo D.J., Poeloengasih C.D. (2019) Adsorption of Methylene Blue dye using Marine algae Ulvalactuca IOP Conf. Ser.: Earth Environ. Sci. 251: 012012.

Przystaś W., Zabłocka-Godlewska E., Grabińska-Sota E. (2013) Effectiveness of Dyes Removal by Mixed Fungal Cultures and Toxicity of Their Metabolites. Water Air Soil Pollut. 224: 1534.

Rajamani M., Rajendrakumar K. (2019) Chitosan-boehmite desiccant composite as a promising adsorbent towards heavy metal removal. J. Environ. Manage. 244: 257-264.

Rajhans G., Sen S.K., Barik A., Raut S. (2020) Elucidation of fungal dye-decolorizing peroxidase $(D y P)$ and ligninolytic enzyme activities in decolorization and mineralization of azo dyes. J. Appl. Microbiol. 129(6): 1633-1643.

Rani B., Kumar V., Singh J., Bisht S., Teotia P., Sharma S., Kela R. (2014) Bioremediation of dyes by fungi isolated from contaminated dye effluent sites for bio-usability. Braz. J. Microbiol. 45(3): 1055-1063.

Roy D.C., Biswas S.K., Saha A.K., Sikdar B., Rahman M., Roy A.K., Prodhan Z.H., Tang, S.S. (2018) Biodegradation of Crystal Violet dye by bacteria isolated from textile industry effluents. Peer J. 6: 5015.

Shabani M., Haghighi M., Kahforoushan D., Haghighi A. (2019) Mesoporous-mixed-phase of hierarchical bismuth oxychloridesnanophotocatalyst with enhanced photocatalytic application in treatment of antibiotic effluents. J. Clean. Prod. 207: 444-457.

Sharma I. (2021) Bioremediation Techniques for Polluted Environment: Concept, Advantages, Limitations, and Prospects. [In:] Trace Metals in the Environment - New Approaches and Recent Advances. Intech. Open, 7. January.

Singh L. (2017) Biodegradation of Synthetic Dyes: A Mycoremediation Approach For Degradation/Decolourization Of Textile Dyes And Effluents. J. Appl. Biotechnol. Bioeng. 3(5): 430-435.

Singh R.L., Singh P.K., Singh R.P. (2015) Enzymatic decolorization and degradation of azo dyes $-A$ review. Int. Biodeterior. Biodegr. 104: 21-31.

Srinivasan A., Viraraghavan T. (2010) Decolorization of dye wastewaters by biosorbents: A review. J. Environ. Manage. 91(10): 1915-1929.

Sudha M., Saranya A., Selvakumar G., Sivakumar N. (2014) Microbial degradation of Azo Dyes: A review. Int. J. Curr. Microbiol. App. Sci. 3(2): 670-690.

Sun J., Li W., Li Y., Hu Y., Zhang Y. (2013) Redox mediator enhanced simultaneous decolorization of azo dye and bioelectricity generation in air-cathode microbial fuel cell. Bioresour. Technol. 142: 407-414.

Sweety, Vats S., Kumar M., Kumar V., Gupta S., Garg S.K. (2017) Nitrogen and Carbon Sources Influencing Mycoremediation of Textile Dyes Using Novel Autochthonous Fungal Isolates. Anal. Chem. Lett. 7(5): 632-646.

Tamirat, A.G., Guan X., Liu J., Luo J., Yongyao X. (2020) Redox mediators as charge agents for changing electrochemical reactions. Chem. Soc. Rev.10: 1039.

Tan L., He M., Song L., Fu X., Shi S. (2016) Aerobic decolorization, degradation and detoxification of azo dyes by a newly isolated salt-tolerant yeast Scheffersomycesspartinae TLHS-SF1. Bioresour. Technol. 203: 287-294.

Varjani S., Upasani V.N. (2019) Influence of abiotic factors, natural attenuation, bioaugmentation and nutrient supplementation on bioremediation of petroleum crude contaminated agricultural soil. J. Environ. Manage. 245: 358-366.

Verma A., Agarwal M., Bhati D., Garg H. (2019) Investigation on the Removal of Direct Red Dye Using Aspergillus Niger. J. Mat. Sci. Surf. Eng. 6(6): 881-883. 
Wang Na., Chu Y., Wu F., Zhao Z., Xu X. (2017) Decolorization and degradation of Congo red by a newly isolated white rot fungus, Ceriporialacerata, from decayed mulberry branches. Int. Biodeterior. Biodegradation. 117: 236-244.

Yang S.B., Hu J., Chen C.L., Shao D.D., Wang X.K. (2011) Mutual effects of $\mathrm{Pb}$ (II) and humic acid adsorption on multiwalled carbon nanotubes/polyacrylamide composites from aqueous solutions. J. Environ. Sci. Technol. 45 (8): 3621-3627.

Yang B., Feng L.D., Zhang L.Y. (2012) Decolorization of wastewater containing reactive brilliant blue dyes by laccase. Chin. J. Environ. Eng. 6 (10): 3514-3518.
Yang J., Yang X., Lin Y., Ng T., Lin J., Ye X., Hildén K. (2015) Laccase-catalyzed decolorization of malachite green: performance optimization and degradation mechanism. PLOS ONE. 10(5): 0127714.

Zahran S.A., Ali-Tammam M., Hashem A.M., Aziz R.K., Ali A.E. (2019) Azoreductase activity of dye-decolorizing bacteria isolated from the human gut microbiota. Sci. Rep. 9: 5508 . 